\title{
Towards Sustainable Potato Production: Partnering to Support Family Farmers in Africa
}

\author{
Hans Dreyer ${ }^{1}$ \\ Received: 3 January 2018 / Accepted: 16 January 2018 / \\ Published online: 19 June 2018 \\ (C) The Author(s) 2018
}

\begin{abstract}
This paper highlights the current developments towards the sustainable intensification of crop production to combat hunger and malnutrition. It also stresses the specific role the cultivation of potato can play in abolishing hunger and malnutrition. Finally, it describes the role of the Food and Agriculture Organization of the United Nations in achieving sustainable intensification of potato production.
\end{abstract}

Keywords European Commission · Food and Agriculture Organization of the United Nations (FAO) $\cdot$ International year of potato $\cdot$ Potato $\cdot$ Save and grow $\cdot$ Seed $\cdot$ Sustainable intensification of crop production systems

\section{Introduction}

The Food and Agriculture Organization of the United Nations (FAO), in unison with its member countries and development partners, leads efforts aimed at achieving a world free from hunger as committed to in the 2030 Agenda. However, the abolishment of hunger and hidden hunger caused by malnutrition requires that $60 \%$ more food will be produced over the next four decades to feed an ever-increasing population. This is a daunting challenge. The difficulties are exacerbated by the confluence of climate change, socioeconomic pressures and the inelasticity of natural resources, especially arable land and water resources. There is, nonetheless, a unanimity of opinion that the significantly more food that is required must be produced largely through enhanced productivities, i.e. attaining higher yields per unit of external inputs. Universally viable solutions must therefore include the transition to the Sustainable Intensification of Crop Production Systems, or Save and Grow, whereby ecosystem services are harnessed to

Hans Dreyer

Hans.Dreyer@fao.org

1 Food and Agriculture Organization of the United Nations (FAO), Viale delle Terme di Caracalla, Rome, Italy 
complement external inputs. Potato, with an annual global production in excess of 370 million metric tons, is the third most important crop and therefore critical to this quest of abolishing hunger sustainably within a generation.

\section{Development and Conclusion}

A major outcome of the 2008 United Nations International Year of Potato was the revalidation of the vital importance of potato to global food systems and nutrition. Furthermore, the International Year, by identifying potato as a 'food of the future', also underscored the potentials for the increased cultivation of the crop, especially in developing countries where the vast majority of the food insecure and malnourished live. Potato is therefore an extremely useful crop for the quest to "end hunger, achieve food security and improved nutrition and promote sustainable agriculture" and the other Sustainable Development Goals by 2030. The extremely rich genetic diversity of potato can contribute to the achievements of agricultural production systems that both harness and support biodiversity; this genetic diversity can also aid countries in achieving their commitments to the Paris Climate Agreement and in deriving the most benefit from the Decade of Action on Nutrition which is running from 2016 to 2025. Great progress is being made with an FAO-implemented project which is funded by the European Commission to strengthen the crop's value chain in sub-Saharan Africa. This is a region of the world where a recalcitrant food insecurity and malnutrition remain endemic. At the same time, this region is forecasted to be the most vulnerable to the vagaries of climate change. A major issue in sub-Saharan Africa is the farmers' suboptimal access to potato planting materials. This is a major constraint to an effective market-oriented value chain for the crop. Public-private partnerships and other forms of multi-stakeholder approaches are extremely important for addressing this and other critical constraints to realising the full potentials of potato, particularly in sub-Saharan Africa where the potentials for the crop's growth are enormous.

Acknowledgements The Food and Agriculture Organization of the United Nations for, inter alia, leading the International Year of Potato and supporting global efforts to transition to Sustainable Intensification of Crop Production Systems. The European Commission for the generous funds in support of the multi-country project, "Strengthening linkages between small actors and buyers in the Roots and Tubers sector in Africa".

Open Access This article is distributed under the terms of the Creative Commons Attribution 4.0 International License (http://creativecommons.org/licenses/by/4.0/), which permits unrestricted use, distribution, and reproduction in any medium, provided you give appropriate credit to the original author(s) and the source, provide a link to the Creative Commons license, and indicate if changes were made. 